\title{
Exploration and Practice of Students' Practical and Innovative Ability Cultivation Mode Based on Academic Competitions
}

\author{
Huicai Chen \\ College of Weifang, Weifang Shandong, 261061,China
}

\begin{abstract}
Key words: Academic competitions, University student, Practical and creative abilities, Training
\end{abstract} mode.

\begin{abstract}
Academic competitions are an effective means of colleges and universities to cultivate innovative talents. Practice and innovative talent training mode reform can effectively promote the enhancement of the quality of education. This paper presents the connotation of academic competitions in order to develop practical and innovative ability of college students. And proposed a mechanism to effectively operate academic competitions from five aspects, that is , cooperating with enterprises, college and school interactive, teacher-student interaction, interaction between students and interdisciplinary interaction. This paper also concluded the successful practice in academic competitions of School of Economics and Management of Weifang University.
\end{abstract}

\section{Significance of discipline competition for training college students' practical innovation ability}

\section{Significance of discipline competition}

Discipline competition is an effective means for colleges to train innovative talents. In the No. 1 document of the Ministry of Education and the Ministry of Finance of 2001, it is clearly proposed to include discipline competition into the major construction of "reform and innovation in practical teaching and talent training mode" and to "chiefly subsidize college students' competition activities with a great impact and extensive participation, stimulate college students' interest and potential and train college students' teamwork awareness and creative spirit”. Besides, the document also fully affirms the important function and significance of discipline competition. New requirements for reform in the innovative talent training mode have also been put forward in the Outline of National Medium-and Long-Term Program for Education Reform and Development (2010-2020). In recent years, in order to promote the training of innovative talents and continue deepening the reform in education and teaching, domestic colleges have carried out discipline competition activities, which also have become a new development approach attracting widespread concern and attention. Discipline competition, which has the demonstrative and guiding effects, can effectively promote discipline construction, specialized teaching, facilitate the reform in curriculum system, teaching contents and methods, advocate the learning style of combining theories with practice, help to train college students' practical innovation abilities such as self-study ability, discovery ability, aesthetic ability, practical ability, organizing ability and communication \& coordination ability. Meanwhile, it is also an important window for all colleges to show their school-running level, education quality and students' comprehensive quality.

\section{Significance of reform in practical innovative talent training mode based on discipline competition}

The practical innovative talent training mode based on discipline competitions uses discipline competitions as auxiliary means and teaching reform as the main body to constantly improve the 
education and teaching quality and enhance students' comprehensive quality. On the one hand, discipline competitions promote teaching reform; on the other hand, teaching reform promotes the enhancement of competitions. The two are complementary and also improve each other. The organic combination of the two can help to improve education and teaching quality, establish a new three-dimensional talent training mode and thus train students' sustainably developing vocational ability. Through the reform in education and teaching, a teaching system which complies with colleges' practical conditions and has characteristics can be established and compound and application-oriented highly-competent talents with practical innovation ability can be trained. In recent years, the School of Economics and Management of Weifang University has been actively organizing students to participate in the "Challenge Cup" Business Plan Competition, "Challenge Cup” Extracurricular and Academic Contest, National College Students' Network Business Innovation Application Contest, Foreign Trade Practice Ability Contest, College Finance and Accounting Contest and other discipline competitions, has achieved excellent results and accumulated certain experience. Thus, it is of very important promotional value and application prospect to explore the practical innovative talent training mode based on discipline competition accordingly.

\section{Discipline competition connotation enhancement mode centering on training college students' practical innovation ability}

\section{Combination of discipline competitions and practical teaching}

Use discipline competitions as a major part of practical teaching activities. Integrate discipline competition activities into open experiments, special business training, centralized course practice and other parts by using discipline competitions as carriers and tongs. Form the practical teaching mode relying on discipline competitions and aiming to train application-oriented talents. At last, achieve the goal of promoting teaching, learning and training with competitions.

\section{Combination and discipline competitions and opening of teaching resources}

Based on all discipline competitions, design innovative experiment projects, form open experiment libraries, and attract more students to participate in discipline competition activities by taking the open experiment as an elective course. Take full advantage of colleges' laboratories, computer rooms, all practical training centers and other teaching resources to provide effective hardware support for discipline competitions.

\section{Combination of discipline competitions and scientific research}

Strengthen the research and development of electives related to discipline competitions and enhance the degree of participation of all discipline competitions through curriculum development. Optimize the course teaching system, encourage all full-time teachers to effectively combine their subjects of scientific research with the topics of discipline competitions, promote the transformation of scientific achievements and effectively solve the problem of the lack of sources of discipline competitions through discipline competitions.

\section{Combination of basic knowledge and specialized knowledge}

Pay attention to the function of discipline competition in combining basic knowledge with specialized knowledge, encourage interdisciplinary crossing and integration, use discipline competitions as carriers to combine the basic knowledge with specialized knowledge students have leaned so as to realize the systematic integration of knowledge and digestion of all curriculum knowledge. During the participation and guidance of discipline competitions, achieve both students and the instructors' joint improvement in knowledge. 


\section{Combination of discipline competition results and transformation}

A perfect disciplinary competition result transformation mechanism is a long-term mechanism to promote the development of discipline competitions. Make the best of on-campus and off-campus resources to well transform and systemize the discipline competition results. For example, study discipline competitions by setting up the project of teaching reform; excellent schemes generated in discipline competitions can be transformed into practical teaching cases, which, then, can be included into the case library of a college or a school; excellent results generated in discipline competitions can by transformed into projects of practical values through university-enterprise cooperation, part-time generalization and other channels. Make efforts to achieve the secondary development and utilization of students' competition results, because college students can have their practical innovation ability further improved in this process.

\section{Discipline competition operating mechanism centering on training college students' practical innovation ability}

\section{University-enterprise interaction mechanism}

Formulate the interaction mechanism between discipline competitions and enterprises. Various forms below can be adopted: enterprises sponsor completion software and hardware; enterprises become title sponsors; enterprises provide competition topics; enterprises provide mentors for competition guidance; enterprises provide probation internship opportunities; enterprises carry out propaganda for relevant businesses; industrial personnel participate in performance evaluation. Actively promote the application and inspection of some discipline completion results in enterprises and realize university-enterprise interaction as well as the win-win of enterprise values and students' ability enhancement.

\section{University-school interaction mechanism}

Formulate the university-school interaction mechanism of discipline competitions. Construct discipline competition systems suitable for the characteristics of students of the schools based on the discipline structure of all secondary schools. Actively organize competitions at school level or above and set up the school-level competitions highlighting specialty characteristics. Make enough communications in the process of a discipline competition and innovatively carry out work based on the responsibilities of colleges and schools.

\section{Teacher-student interaction mechanism}

Take full advantage of existing educational resources to build a stable and reasonable competition participation and guiding team. Effectively combine students' participation in competitions with instructors' guidance and comprehensively embody teacher-student interaction in selection of instructors, ways of teacher-student communication and information feedback mechanism etc. Try to carry out the mission-style training and simulation competition mode in part of theoretical and practical teaching, implement the exploratory and study-discussion educational and teaching methods to improve the effect of teacher-student interaction.

\section{Student-student interaction mechanism}

Conduct the selection, training and echelon construction of competitors and actively give play the functions of student societies and associations at all levels in the selection and echelon training of members of discipline competition projects. Encourage students to set up various competition groups dominated by college students' self-management based on discipline competition activities. Establish the competitors' information recording and exhibition platforms, record the course of group competition, and exhibit the successful experiences of all previous excellent group graduates. Set up a bridge of communication between all previous prize winners and new members in virtue of the network platform, consolidate and enhance the echelon construction of competitors. 


\section{Interdisciplinary interaction mechanism}

As many comprehensive discipline competition events have the distinct discipline comprehensiveness and openness and can show more team spirit, students in different specialties should participate. Therefore, in the existing incentive assessment mechanisms, all colleges should establish corresponding interdisciplinary united group modes so as to create conditions for the formation of interdisciplinary instructors and student groups, promote discipline crossing and integration, and comprehensively improve students’ knowledge during the participation.

\section{The School of Economics and Management's Successful practices in promoting college students' training of practical innovation ability via discipline competitions}

\section{The implementation of the mode of "replacing exam with competition" in some courses}

The School of Economics and Management of Weifang University has carried out the educational and teaching reform of "replacing exam with competition" in such courses as Network Marketing and E-Commerce, has implemented the teaching activity view of "promoting teaching, learning and reform with competitions" in combination with each yearly network business innovative application competition for national college students, has made corresponding reforms in the teaching contents, teaching means, evaluation of teaching quality and course assessment mode etc. of relevant courses, has better aroused the enthusiasm of students in relevant specialties, has improved students' ability to solve practical business problems and has made satisfactory achievements. The strategic exam and evaluation mode is adopted in Market Research and Forecasting, Negotiation and Marketing Skills, International Business Negotiation and other courses. The group competition and other ways have achieved the effective evaluation on students' knowledge capability level through on-site demonstration.

\section{Practical application of “ebwinner" innovative practical teaching management platform for Chinese universities}

The "ebwinner" innovative practical teaching management platform for Chinese universities is one of the practical achievements of network business innovative application competition for national college students. As a test unit of the platform, the School of Economics and Management of Weifang University has realized the innovative practical teaching mode combining enterprises' real business items with colleges' teaching contents. The content of university-enterprise cooperation has been applied in the practical teaching of some courses of the school. Besides, the school has also carried out university-enterprise communication and realized teaching management based on software, has effectively organized the mainstream network platforms and enterprises' experienced personnel in traditional enterprises and industry with colleges' teachers, students, practice or experimental courses and has taken full advantage of off-campus resources to achieve the integration and utilization of on-campus and off-campus resources.

\section{Set up the technological entrepreneurship center for college students}

The School of Economics and Management of Weifang University has established the technological innovation center for college students- "Youth Entrepreneurship Association" by relying on the university's Youth League Committee. Through the "simulation company" flow operation management, students can involve in the real "enterprise actions", which can lay a foundation for their future entrepreneurship. The "Youth Entrepreneurship Association" can not only serve as the second classroom for college students but also has the carrier function during the organization and preparation of discipline competitions. Besides, it has also developed into the technological incubation center considering students as the main body, has provided some practical operation chances for relevant discipline competition results, has created powerful conditions for the successful transformation of discipline competition results and has effectively solved the problem of sustainability of competition events. 


\section{Implement the teacher+ "team combination" guiding mode}

As there are such problems as numerous group competitors, extensive topics to be selected and lack of instructors, the School of Economics and Management of Weifang University has implemented the responsible teacher + "team combination" guiding mode in discipline competitions of all types and at all levels; namely, one instructor serves as a responsible teacher to take the lead in each competition event and organize other 3-4 teachers for joint guidance. The guiding mode can not only take full advantage of the specialty advantage of each instructor but also reduce an instructor's burden. Besides, a satisfactory effect has been made, so the guiding mode has been popularized and implemented by many schools participating in competitions.

\section{Design and maintenance of special websites for discipline competitions}

The School of Economics and Management of Weifang University has set up the discipline competition network management platform, which covers the plates such as competition registration system, relevant information on all discipline competitions, cutting-edge knowledge about discipline competitions, test questions of all previous competitions and answer analyses and exhibition of students' competition results, and has connected with the provincial and national websites related to competitions so as to play a role in expanding students' scope of knowledge and deeply understand the cutting-edge development of discipline competitions concerned. Students can apply for participation online, choose instructors, participate in training courses, watch teachers' training courseware online or obtain online answers.

\section{Establish and perfect system and policy guarantee}

Based on the documents such as Implementation Methods for Innovative Credits of Weifang University (Trial) and Provisions of Weifang University on Implementing the Project Instructor System (Trial), the School of Economics and Management of Weifang University has specially introduced Measures for Management and Affirmation of Innovative Credits of the School of Economics and Management, Competition Rewarding Measures of the School of Economics and Management, Rewarding Measures for Outstanding Contributions of the School of Economics and Management and other supporting policies, strengthened the organization and guiding of discipline competitions, effectively aroused the vast teachers and students' enthusiasm about participating in discipline competitions and other technological innovative practical activities, and provided a wholesome system and policy guarantee for the development of various discipline competitions.

\section{Acknowledgement}

Topic name: teaching reform project of Weifang Univeristy, "Innovation and Practice in Discipline Competition Organization and Management Mode for College Students Oriented by Training Innovation Ability"

Toplic No.: 2016YJ033

\section{References}

[1] Bai Yongguo. Study and Practice of “Three-level and Three-direction” Discipline Competition System for College Students. Journal of Jilin Institute of Chemical Technology, 2012 ,(10).

[2] Xia Lingna. Analysis and Countermeasures for Problems in Discipline Competitions in Local Colleges. Journal of Zhejiang Ocean University, 2014,32(2)

[3] Zeng Qingjun and Zeng Xiaosong. Construction and Practice of Multilevel and All-dimensional Discipline Competition System Oriented by Training College Students' Practical Innovation Ability. Journal of Chongqing Technology and Business University (Natural Science), 2012,(4) 
[4] He Ying. Security Mechanism for Discipline Competition Activities of Students in Application-oriented Universities. Jiangsu Social Sciences, 2011,(12)

[5] He Xin and Zhang Mei. Discussion on Discipline Competitions' Promoting the Training of Application-oriented Talents and Deepening the Practical Teaching Reform. The Guide of Science \& Education, 2015, (7).

[6] Yang Hongzhen and Ma Xizhen. Study on Reform in Practical Teaching to Train College Students' Practical Ability and Innovation Ability in Local Colleges. Educational Management, 2014, (6). 